ORIGINAL ARTICLE

\title{
Physiological criteria of functional fitness and determinants of physical work capacity of highly skilled wrestlers
}

\author{
Oleksander Pryimakov $^{1 \mathrm{ACDE}}$, Sergii Iermakov ${ }^{2 \mathrm{CDE}}$, Jerzy Eider ${ }^{1 \mathrm{ADE}}$, Stanislav Prysiazhniuk ${ }^{3 \mathrm{ADE}}$, Natalija Mazurok ${ }^{4 \mathrm{DE}}$ \\ ${ }^{1}$ Szczecin University, Poland \\ ${ }^{2}$ Gdansk University of Physical Education and Sport, Poland \\ ${ }^{3}$ State University of Telecommunications, Kyiv, Ukraine \\ ${ }^{4}$ National Pedagogical Dragomanov University, Kyiv, Ukraine
}

Authors' Contribution: A - Study design; B - Data collection; C - Statistical analysis; D - Manuscript Preparation; E - Funds Collection

\begin{abstract}
Purpose: $\quad$ The objective of the work is to study the key factors of highly skilled wrestler fitness structure determining the level of their functional state and physical work capacity at the stage of maximum realization of individual capacities.

Material: $\quad 45$ highly skilled wrestlers aged 19-27 years, members of the national teams of Ukraine in freestyle and Greco-Roman wrestling were examined. The 27 of Ukrainian National Team athletes, participated in this study, were at the student's age (19-24 y) during championships and 23 of them were currently students. Instrumental research methods were used to record indices of functional fitness (FF) and physical work capacity of wrestlers while performing a specialized test with throws of a partner and a block of testing physical loads on a bicycle ergometer.

Results: It was revealed that among factors determining the structure of wrestlers' fitness, the integral factor of FF general level (31.13\% of the total variance) has the greatest impact on the variability of physical work capacity indices of athletes. Increase in skill level of wrestlers is associated with decreased time of performing throws in a specialized test, increased relative values of lactate power, $\mathrm{O} 2$-debt, general level of $\mathrm{FF}, \mathrm{O} 2$ consumption per $1 \mathrm{~kg}$ of body mass. Improvement of wrestler FF structure along with an increase in their skill level is characterized by higher contribution of FF integral parameters (anaerobic power, mobility of physiological reactions, FF general level) to the manifestation of physical work capacity. It was revealed that the general level of FF of wrestlers is characterized by the following ratio of key factors (relative to model values of elite athletes): anaerobic power $-52.6 \pm 4.9 \%$, aerobic power $-52.8 \pm 4,1 \%$, mobility $-80.4 \pm 5.3 \%$, economy $-43.3 \pm 3.0 \%$. In the course of studies, mathematical models of the key factors of wrestler FF structure associations with the level of special work capacity, skill level and weight category have been developed. Modeling allowed to specify the criteria and develop scales for assessing special physical work capacity level, differentiated according to skill level and weight category groups of highly skilled wrestlers.

Conclusions: The findings reflect the crucial role of anaerobic energy supply mechanisms in the manifestation of high special work capacity in wrestling. Improvement of wrestler FF structure along with the increase of their skills is characterized by a decrease in the number of key functional parameters determining the level of physical work capacity during testing with loads that model specific activity of highly skilled wrestlers. This, along with body functions economization, is one of the important criteria for improving FF structure of the combat athletes.

Keywords: wrestlers, functional fitness, criteria, work capacity, models.
\end{abstract}

\section{Introduction}

The specifics of the long-term sports training and competitive activity of highly skilled wrestlers determines the formation of fitness structure (FS) of combat athletes, with a certain level of development and ratio of strength, speed-strength and coordination qualities, special endurance, speed of response, functional state [1-4]. Functional fitness (FF) of athletes is one of the major components of combat athlete FS. According to researchers reserves of anaerobic alactate, anaerobic lactacidal and aerobic energy supply systems represent the key integral indices of FF [5-7]. Some works show that the level of development and association of the key components of combat athlete FS tend to determine the o Oleksander Pryimakov, Sergii lermakov, Jerzy Eider,

Stanislav Prysiazhniuk, Natalija Mazurok., 2020

doi:10.15561/20755279.2020.0403 level of their special work capacity [8-11].

Analysis of literary sources showed insufficient investigation of the ratio and associations of individual FS components between each other and sports result in wrestling [9, 12-14].

Despite different approaches, most works presented a disparate material characterizing certain aspects of wrestlers' fitness: physical development [1, 1517], functional state [18-21], level of development of individual motor qualities $[1,22,23]$.

The coverage of wrestler FF structure, identification of the key factors and associations determining its level and that of special work capacity of athletes of different weight categories, the level of fitness and skill level are insufficiently studied from the perspective of a system approach [25]. 
The provisions and principles of a system approach in biology are necessary to specify and detail the mechanisms of body system integrative activity, their interaction in the process of adaptation to high training and competitive loads, and to improve the level of competition form [25]. Coverage of the complex of questions posed would have permitted to reasonably and purposefully approach the management of functional system adaptive reorganizations, increase special fitness level of combat athletes and effectively influence the growth of their special work capacity and sports results.

Despite the fact that the integrative activity of the body of combat athletes was addressed in some publications [2, 24], its coverage cannot be considered sufficient.

Insufficient coverage of the integrative activity of the body of combat athletes of different weight categories, skill level, sex, specialization, as well as its insufficient study from the complex and systemic standpoint, the importance for the theory and practice of wrestling determined the choice of the direction of this study.

The objective of the work is to study the key factors of highly skilled wrestler fitness structure determining the level of their functional state and physical work capacity at the stage of maximum realization of individual capacities.

\section{Material and methods}

Participants. 45 highly skilled wrestlers aged 1927 years, members of the national teams of Ukraine in freestyle and Greco-Roman wrestling were examined: candidates for masters of sports (CMS), masters of sports (MS), international masters of sports (IMS) and merited masters of sports (MMS). The 27 of Ukrainian National Team athletes, participated in this study, were at the student's age (19-24 y) during championships and 23 of them were currently students. Study protocol was approved by Ethic Committee University. The research was fulfilled in compliance with WMA Declaration of Helsinki - Ethical Principles for Medical Research Involving Human Subjects [26].

Studies were conducted at precompetitive stage of annual preparation cycle.

Instrumental research methods were used to register indices of functional state, speed-strength fitness and special work capacity of wrestlers $[2,9]$.

Anaerobic testing was used to assess the level of special work capacity: wrestlers performed throws of a partner of equal weight at maximum pace. Greco-Roman wrestlers performed one hand forward bending throws, whereas free-style wrestlers - those with shoulder and hip hold. Tests were carried out at maximum pace: each athlete performed 3-5 series of 15 throws in each series in the shortest possible time with 1-minute rest interval between series $[2,9]$. The structure and intensity of throws performed in the test reflected the structure and intensity of the motions executed in the wrestle. Special work capacity was assessed according to the time of performing individual throw, total time of performing 15 throws in each series and total time of performing the sum of throws in the test. The coefficient of special work capacity was also calculated as the ratio of the total time of performing throws in the test to the best ("reference") time shown in one of the series, multiplied by 3 (or 5) [2]. The intensity of performed load during testing was controlled by HR using Polar sport testers (Fig. 1).

Testing on a bicycle ergometer with registration of physiological system activity indices during a block of testing loads performance was also used for a more complete assessment and specification of the mechanisms that determine physical work capacity and FF.

According to the results of the battery of testing load performance, a complex of 9 indices was calculated, on the basis of which such key factors of FF structure as anaerobic power, mobility and economy were differentiated in accordance with specially developed algorithm [27-30]. On the basis of formalized point assessment of indices, the general level of FF and the degree of development of studied structural properties were determined.

Such a differentiation of the body functional capacities allowed to single out the most generalized properties of FF structure, which lend themselves to targeted improvement by means of specially selected training effects $[5,28,31$ 33].

In the process of performing loads on a bicycle ergometer, the following initial indices were determined: respiratory minute volume $\left(1 \cdot \mathrm{min}^{-1}\right)(\mathrm{RMV})$, concentration of oxygen $\left(\mathrm{O}_{2}\right)$ and carbon dioxide $\left(\mathrm{CO}_{2}\right)$ in exhaled air $(\%)$, heart rate (beats $\left.\cdot \min ^{-1}\right)(\mathrm{HR})$ and corresponding indices of the power of load performed (W).

The model characteristics of the key factors in FF structure of wrestlers and their associations with the level of special work capacity, skill level and weight category were also determined. The results obtained on the models were modeled and compared with the real values of athletes' FF, the level of their special work capacity; estimation scales and practical recommendations were developed.

To examine the body FF, the "Oxycon Pro" automatic gas analyzer of Jeager (Germany) and the AsCARD MrGrey v.07.205 electrocardiograph of ASPEL S.A (Poland) were used.

The battery of testing loads was performed on a "Monark" bicycle ergometer (Sweden) according to the following algorithm: 1) state of rest - 3 minutes; 2) load of standard (moderate) power $-6 \mathrm{~min}(2 \mathrm{~W}$ per $\mathrm{kg}$ of weight); 3) load of anaerobic power lasting 30 seconds; 5) load of anaerobic power lasting 60 seconds. Pauses of recovery between performing test loads were filled with unloaded pedaling.

Statistical analysis. STATISTICA 13.5 statistical software package was used for processing experimental material. The methods of regression, factor and canonical analysis were applied [34].

\section{Results}

Application of factor analysis methods during processing of the results obtained in the experiment allowed to identify 7 key factors in the structure of FF of highly skilled wrestlers (Fig. 2).

Among the identified factors, the greatest partial 


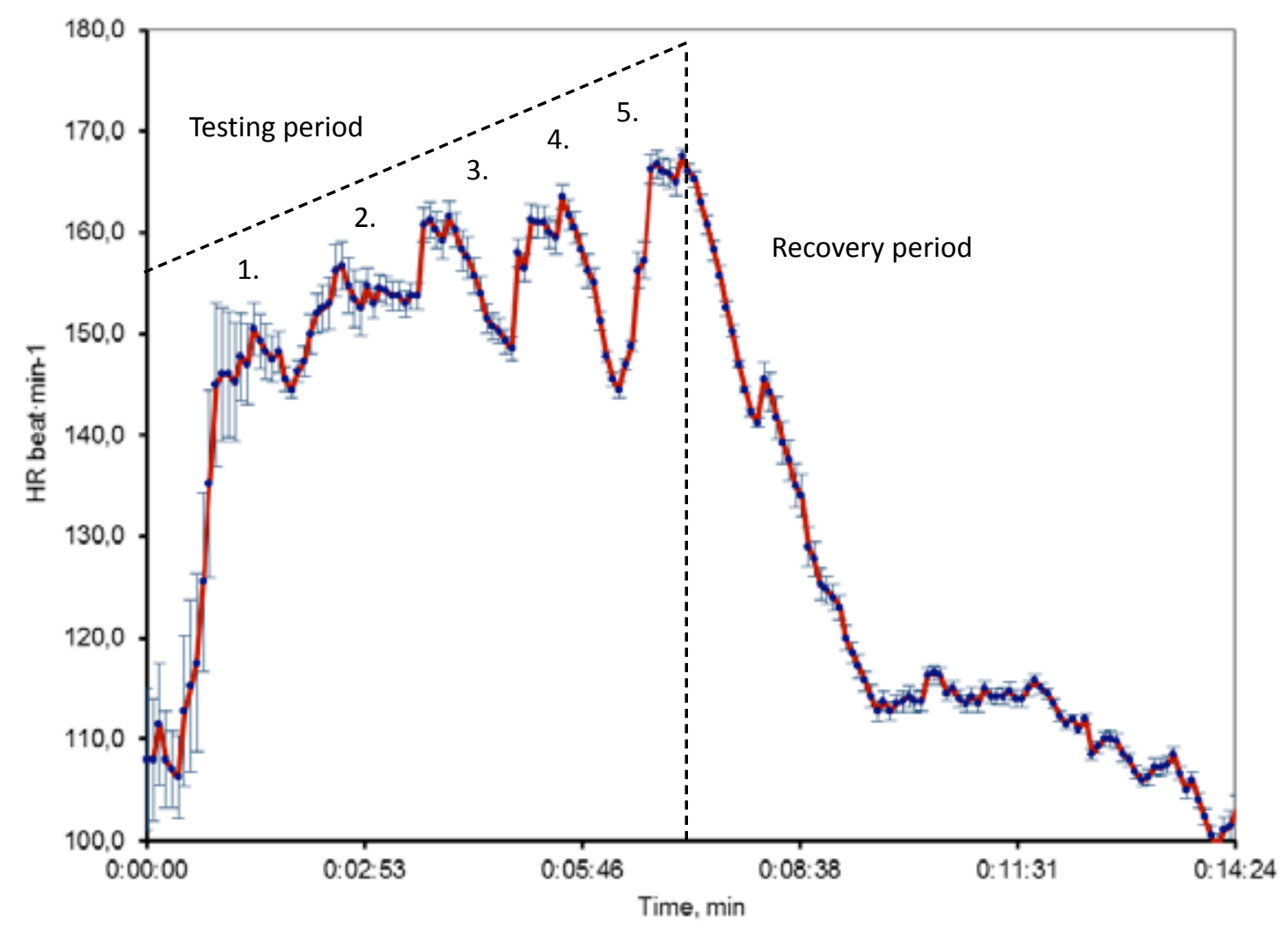

Fig. 1. Heart rate dynamics during performing 5 series of 15 throws at a maximum pace with 1-minute rest interval between series (average data for a group of wrestlers): 1-5 - mark of the series of performed throws

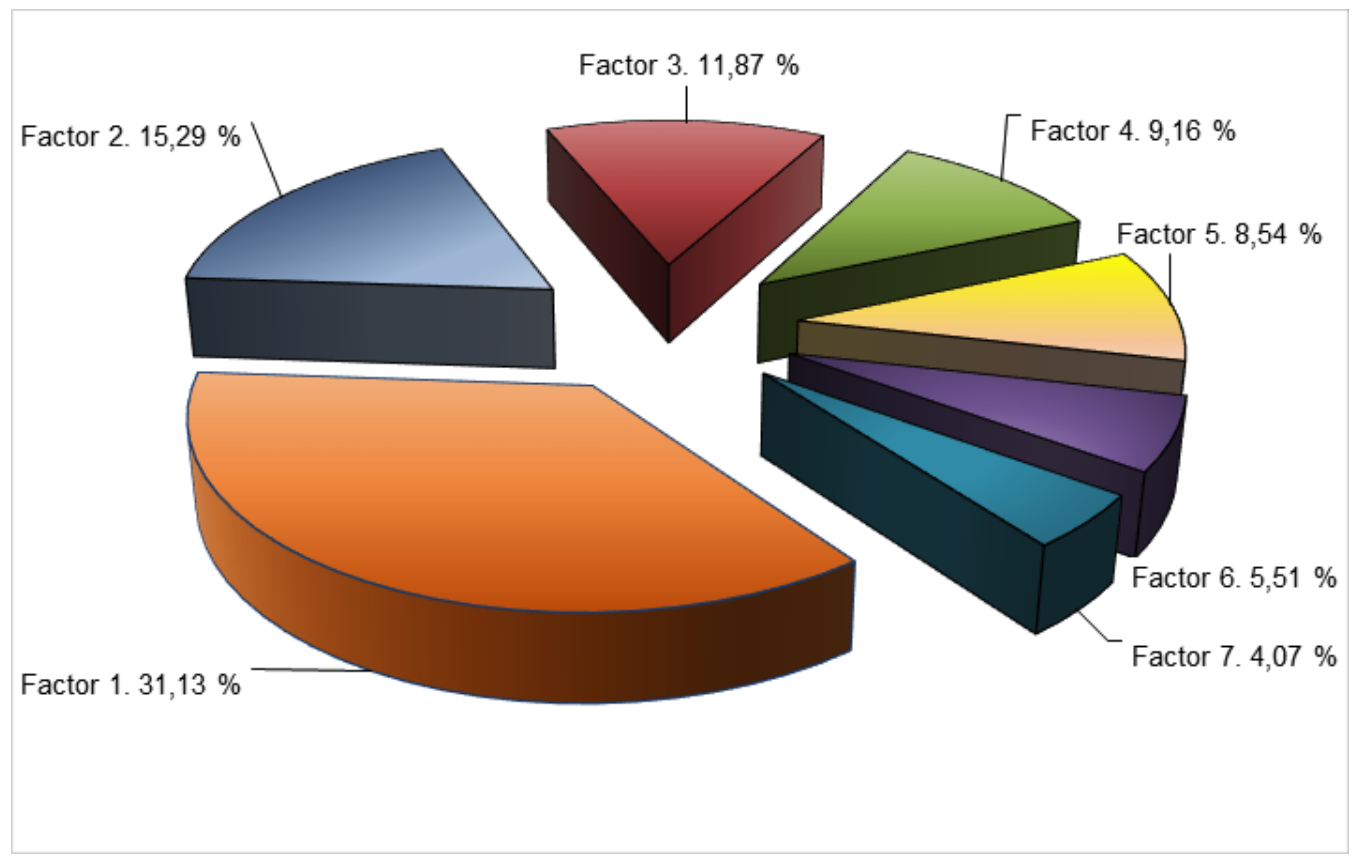

Fig. 2. Key factors of highly skilled wrestler functional fitness: 1 - general level of FF; 2 - cardiovascular system functional state in basal conditions; 3 - power of anaerobic energy supply system; 4 - efficiency of aerobic energy supply mechanism; 5 - state of regulatory mechanisms of cardiac function; 6 - cardiac muscle excitability; 7 - cardiac muscle metabolism. 
contribution to the variability of generalized dispersion of the body functional and metabolic indices is made by the integral factor, which we called the factor of functional fitness general level (31.13\% of the total dispersion).

Based on the identified factors, the key indices of wrestler FF structure were determined: alactate and lactate power, maximum oxygen consumption $\left(\mathrm{VO}_{2} \max \right)$, maximum RMV, average HR and watt pulse of standard work, general aerobic potential realization, economy, general level of FF, mechanical work efficiency, ventilatory equivalent of standard work, resting heart rate under basal conditions, amplitude of the $\mathrm{P}$ and $\mathrm{R}$ waves of the electrocardiogram.

Correlation analysis demonstrated that wrestler skill level improvement (from candidates to merited masters of sports $)$ is associated with increase of lactate $(r=0.609, p$ $=0.01)$ and anaerobic $(r=0.840, p<0.01)$ power, mobility of physiological processes $(r=0.777, p<0.01)$, general level of FF ( $r=0.716, p<0.01)$, blood hemoglobin concentration and a decrease of $\mathrm{HR}$ in basal conditions $(\mathrm{r}$ $=-0.725, \mathrm{p}<0.01)$ and during standard work $(\mathrm{r}=-0.552$, $\mathrm{p}<0.01$ ), and blood lactate concentration.

Improvement of wrestler skill level is also accompanied by an increase in $\mathrm{O}_{2}$-debt during testing on a bicycle ergometer with maximum intensity, mechanical work efficiency and work capacity while performing a specialized test with throws $(\mathrm{r}=0.550<0.01)$.

Table 1 presents coefficients of the key functional indices' correlation with the level of special work capacity of combat athletes during specialized test performance.

Improvement of wrestlers' skill level is accompanied by reduced time of performing throws in specialized test, increased relative values of lactate power, $\mathrm{O}_{2}$-debt, $\mathrm{FF}$ general level and $\mathrm{O}_{2}$ consumption per $1 \mathrm{~kg}$ of body mass. This reflects the major role of anaerobic energy supply mechanisms in the manifestation of special work capacity in wrestling.

Analysis of the results obtained using a block of sequentially performed non-specific testing loads with registration of 59 parameters of respiration, cardiac activity and special work capacity indicated that improvement of wrestler FF structure along with the increase of their skill level is characterized by enhanced contribution of FF integral parameters to the manifestation of athletes' special work capacity - anaerobic power, mobility of physiological reactions, general level of FF. Furthermore, the number of key functional indices determining the result in special work capacity test tends to decrease. Along with function economization, this is an important criterion for perfection of FF structure.

General level of wrestlers FF evaluation according to vegetative reactions in response to performed testing loads and achieved indices of work capacity showed that in combat athletes it is characterized by the following ratio of key factors (relative to model values of elite athletes): anaerobic power $-52.6 \pm 4.9 \%$, aerobic power $-52.8 \pm$ $4.1 \%$, mobility - $80.4 \pm 5.3 \%$, economy $-43.3 \pm 3.0 \%$.

In these components of functional fitness, GrecoRoman wrestlers have an advantage over freestyle wrestlers. During sequential performance of physical loads (from standard aerobic to intensity extreme - anaerobic), Greco-Roman wrestlers exhibit higher anaerobic power and recovery rate after anaerobic load. Freestyle wrestlers demonstrate higher recovery rate after standard aerobic load.

Analysis of the relationships between the key individual and integral indices of FF, on the one hand, and the general level of FF, the level of special work capacity, skill level and weight category, on the other hand, allowed to formalize the revealed dependences in mathematical models.

For instance, in models $1-3$, presented below, the dependences of the general level of wrestler FF on different variants of the ratio and development level of FF structure integral components are reflected (equations $1-3)$ :

Table 1. Associations between functional fitness parameters and special work capacity of wrestlers during performing test with throws.

\begin{tabular}{|c|c|c|c|c|c|}
\hline \multirow{2}{*}{ Indices } & \multicolumn{4}{|c|}{ Time of performing throws in 3 series, $s$} & \multirow{2}{*}{$\begin{array}{l}\text { Work capacity } \\
\text { coefficient }\end{array}$} \\
\hline & 1 series & 2 series & 3 series & Total time & \\
\hline $\mathrm{VO}_{2} \mathrm{ml} \cdot \mathrm{min} \cdot \mathrm{kg}^{-1}$ & $-0.494 *$ & $-0.548^{*}$ & $-0.514 *$ & $-0.627^{*}$ & $0.466^{*}$ \\
\hline $\mathrm{RMV}, \mathrm{I} \cdot \mathrm{min}^{-1}$ & -0.015 & 0.106 & 0.141 & 0.092 & -0.387 \\
\hline Anaerobic power,\% & $-0.653^{*}$ & $-0.551^{*}$ & $-0.487^{*}$ & $-0.631^{*}$ & 0.198 \\
\hline Lactate power, wt $\cdot \mathrm{kg}^{-1}$ & $-0.871 *$ & $-0.825 *$ & $-0.830 *$ & $-0.871^{*}$ & $0.675^{*}$ \\
\hline $\mathrm{O}_{2}$-debt, $\mathrm{ml} \cdot \mathrm{kg}^{-1}$ & -0.509 & $-0.514^{*}$ & -0.399 & $-0.560^{*}$ & 0.025 \\
\hline Wt pulse of standard work & 0.258 & 0.394 & $0.509 *$ & $0.419 *$ & $-0.387^{*}$ \\
\hline GAPR* & 0.018 & 0.135 & 0.202 & 0.137 & -0.182 \\
\hline Mobility, \% & $-0.725^{*}$ & $-0.649 *$ & $-0.575^{*}$ & $-0.719 *$ & 0.227 \\
\hline Economy, \% & 0.233 & $0.392^{*}$ & $0.491^{*}$ & $0.404^{*}$ & $-0.364 *$ \\
\hline FF general level, \% & $-0.612^{*}$ & $-0.516^{*}$ & $-0.435^{*}$ & $-0.653^{*}$ & 0.181 \\
\hline HR in prone position, bt. $\mathrm{min}^{-1}$ & $0.625^{*}$ & $0.621^{*}$ & $0.572 *$ & $0.656^{*}$ & $-0.343 *$ \\
\hline
\end{tabular}

* Note: asterisk indicates statistically significant correlation coefficients; GARP - general aerobic potential realization, $\% ; \mathrm{PO}_{2}$ - partial oxygen tension. 


$$
\begin{gathered}
y=\left(10,496+0,282 x_{1}+0,312 x_{2}+0,174 x_{3}\right) \pm 3,4 \\
(r=0,988, p<0,001)
\end{gathered}
$$

where: $\mathbf{y}-$ general level of FF, $\%, \mathbf{x}_{1}-$ mobility, $\% ; \mathbf{x}_{\mathbf{2}}-$ anaerobic power, $\% ; \mathbf{x}_{3}-$ economy, $\%$;

$$
\begin{gathered}
y=\left(10,52+0,332 x_{1}+0,252 x_{2}+0,223 x_{3}\right) \pm 3,4 \\
(r=0,989, p<0,001)
\end{gathered}
$$

where: $\mathbf{y}$ - general level of FF, $\%, \mathbf{x}_{1}-$ anaerobic power, $\% ; \mathbf{x}_{2}-$ mobility, $\% ; \mathbf{x}_{3}-$ economy, $\%$.

$$
\begin{gathered}
y=\left(0,931+0,312 x_{1}+0,331 x_{2}+0,336 x_{3}\right) \pm 0,8 \\
(r=0,988, p<0,001)
\end{gathered}
$$

where: $\mathbf{y}$-general level of FF, $\%, \mathbf{x}_{\mathbf{1}}-$ aerobic power, $\% ; x_{2}-$ anaerobic power, $\% ; x_{3}-$ economy, $\%$.

Values of correlation $(\mathbf{r}=\mathbf{0 . 9 8 8}-\mathbf{0 . 9 8 9}, \mathbf{p}<\mathbf{0 . 0 0 1})$ and determination $(\mathrm{d}=\mathbf{0 . 9 7 6} \mathbf{- 0 . 9 7 8}, \mathbf{p}<\mathbf{0 . 0 0 1})$ coefficients are indicative of a high predictive significance of the above models. They permit high-precision prediction of changes in the general level of FF during alteration of individual parameters of the model or their combinations: anaerobic power, mobility, economy.

As a result of modeling, it was found that, of the analyzed components of wrestler FF structure, the anaerobic power parameter has the greatest impact on the general level of FF, whereas that of economy - the least one.

Models 4-5 reflect the influence of individual and integral components of $\mathrm{FF}$ structure on the temporal characteristics of performed throws as indirect characteristics of special work capacity level of wrestlers (equations 4-5):

$$
\begin{gathered}
y=\left(85,32+0,751 x_{1}-0,331 x_{2}\right) \pm 15,1 \\
(r=0,714, p<0,01)
\end{gathered}
$$

where: $\mathbf{y}$ - special work capacity level, s, $\mathbf{x}_{\mathbf{1}}-\mathrm{HR}, \mathrm{bt} \cdot \mathrm{min}$; $\mathrm{x}_{2}-$ general level of FF, $\%$.

$$
\begin{gathered}
y=\left(78,7+2,04 x_{1}-0,825 x_{2}-0,82 x_{3}\right) \pm 14,6 \\
(r=0,744, p<0,01)
\end{gathered}
$$

where: $\mathbf{y}$ - special work capacity level, s, $\mathbf{x}_{1}$ - functional fitness general level, $\% ; \mathbf{x}_{2}-$ anaerobic power, $\% ; \mathbf{x}_{3}-$ mobility, \%;

It is noteworthy that skill level improvement is accompanied by a decrease in the time of executing throws $(\mathrm{r}=-0.571, \mathrm{p}<0.01)$, whereas an increase in body mass (weight category) is succeeded by its increment ( $\mathrm{r}=$ $0.510 \mathrm{p}<0.01)$.

The multiple correlation coefficient $(r=0.721, p$ $<0.00001$ ) and the regression model presented below reflect the specifics of the result dependence upon skill level and weight category of wrestlers during specialized test performance (equation 6):

$$
y=\left(96,1+13,12 x_{1}-18,71 x_{2}\right) \pm 16,3
$$

where: $\mathbf{y}$ - result during performance of 45 throws, $\mathrm{s} ; \mathbf{x}_{1}$ - weight category code: $55-60 \mathrm{~kg}-1 ; 66-74 \mathrm{~kg}-2 ;>84$ $\mathrm{kg}-3 ; \mathbf{x}_{2}-$ skill code: CMS - 1; MS - 2; MMS, IMS - 3 .

Analysis of this model showed that the influence of skill level and body mass can explain the versatility of
$51.9 \%$ of the variability of the total result during execution of throws $(\mathrm{F}=17.2, \mathrm{p}<0.00001)$, whereas $48.1 \%$ of the result variability during performing throws is determined by unaccounted for factors in this analysis.

The studies also revealed that wrestlers' skill level not only affect the level of special work capacity and functional fitness, but, to a large extent, is determined by the parameters of FF structure (equation 7):

$$
\begin{gathered}
y=\left(0623+0,722 x_{1}-0,258 x_{2}-0,2176 x_{3}-0,222 x\right. \\
(r=0,758, p<0,02)
\end{gathered}
$$

where: $\mathbf{y}$ - skill level; $\mathbf{x}_{1}$ - functional fitness general level $\% ; \mathbf{x}_{2}-$ anaerobic power, $\% ; \mathbf{x}_{3}-$ aerobic power, $\% ; \mathbf{x}_{4}-$ economy, $\%$.

Presented model indicates that changes of wrestlers' skill level (their sports mastery) are associated with alterations in the parameters of FF structure - anaerobic and aerobic power, economy, and general level of functional fitness.

In the process of canonical correlation analysis, it was found that the degree of versatility of the group of physical work capacity indices by $36.7 \%$ is determined by the variability of FF indices, whereas the versatility of functional fitness indices by $32.7 \%$ is defined by mechanisms that determine physical work capacity. High values of the canonical correlation coefficient $(\mathrm{R}=0.855)$ and Xi-square $(\chi 2=72.8, p=0.01)$ confirm this.

Developed models and revealed relationships indicate the presence of a positive cross-transfer between parameters of special work capacity and those of FF structure of wrestlers: an increase in the level of FF is associated with enhancement of special work capacity, and vice versa, an increase in special work capacity is connected with augmentation of general functional potential and its individual components. Of these, the anaerobic power parameter, being the key criterion of one of energy supply mechanisms for special work capacity of wrestlers, has the highest specific weight in the general structure of FF.

Models presented in the work served as the basis for development of a system for assessing the level of special work capacity of highly skilled wrestlers, differentiated by skill level and groups of weight categories of athletes (Table 2).

\section{Discussion}

The results of our previous studies and those of a number of authors have shown the advantage of highly skilled wrestlers over less skilled and less prepared athletes in a number of physical fitness key parameters: physical development $[2,9,17]$, functional state $[19,21$, $35]$, special work capacity [8, 36].

Being the components of athlete fitness general structure, parameters of physical development [1], physical [1, 3, 37] and functional [3, 4, 18, 35] fitness, special work capacity $[9-11,36]$ are characterized by different relationships and interactions in athletes of various skill level [2], different weight categories [3] and in the process of their sports mastery alteration [37-40]. 
Table 2. Standard scales for assessing special work capacity of wrestlers of different skill level according to total time (sec) expended on execution of 45 one hand forward bending throws in 3 series (15 throws in each series)

\begin{tabular}{lllllll}
\hline \multirow{2}{*}{ Skill level } & \multirow{2}{*}{ Weight categories, kg } & \multicolumn{5}{l}{ Estimate, point } \\
\cline { 3 - 7 } & & $\mathbf{5 .}$ & $\mathbf{4 .}$ & $\mathbf{3 .}$ & $\mathbf{2 .}$ & $\mathbf{1}$. \\
\hline \multirow{2}{*}{ MMS, } & $55-60$ & $\leq 46.9$ & $47.0 \leq 53.9$ & $54.0 \leq 60.9$ & $61.0 \leq 74.9$ & $75.0 \leq 81.9$ \\
IMS & $66-74$ & $\leq 44.9$ & $45.0 \leq 53.9$ & $54.0 \leq 62.9$ & $63.0 \leq 80.9$ & $81.0 \leq 89.9$ \\
& $>84$ & $\leq 58.9$ & $59.0 \leq 68.4$ & $68.5 \leq 77.8$ & $77.9 \leq 96.8$ & $96.7 \leq 106.2$ \\
\hline \multirow{2}{*}{ MS } & $55-60$ & $\leq 67.0$ & $67.1 \leq 73.0$ & $73.1 \leq 79.1$ & $79.2 \leq 91.2$ & $91.3 \leq 97.3$ \\
& $66-74$ & $\leq 73.6$ & $73.7 \leq 80.3$ & $80.4 \leq 87.0$ & $87.1 \leq 100.4$ & $100.5 \leq 107.1$ \\
& $>84$ & $\leq 88.9$ & $89.0 \leq 94.7$ & $94.8 \leq 100.5$ & $100.6 \leq 112.1$ & $112.2 \leq 117.9$ \\
\hline \multirow{2}{*}{ CMS } & $55-60$ & $\leq 77.4$ & $77.5 \leq 84.7$ & $84.8 \leq 92.1$ & $92.2 \leq 106.7$ & $106.8 \leq 114.1$ \\
& $66-74$ & $\leq 71.2$ & $71.3 \leq 82.8$ & $82.9 \leq 94.4$ & $94.5 \leq 117.6$ & $117.7 \leq 129.2$ \\
& $>84$ & $\leq 97.8$ & $97.9 \leq 105.1$ & $105.2 \leq 112.5$ & $112.6 \leq 127.1$ & $127.2 \leq 134.5$ \\
\hline
\end{tabular}

Despite the fact that these and similar publications characterize various parameters of combat athlete fitness structure, they under-report associations and the ratio of its individual components, both between themselves and with sports results [40-43]. In addition, they fail to sufficiently analyze the factors determining FF general level and the level of work capacity. Physiological mechanisms and criteria of special work capacity are insufficiently differentiated in athletes of different weight categories and skill level.

Analysis of our earlier studies, as well as generalization of findings of this work, suggest that the key mechanisms of FF of highly skilled wrestlers include those that determine the power of the anaerobic energy system, economy of physiological systems functioning at rest and during muscular activity of anaerobic-aerobic nature, the rate of recovery processes, the state of cardiac activity regulatory mechanisms, the level of metabolic processes and cardiac muscle excitability.

The level of special work capacity, anaerobic power, $\mathrm{O}_{2}$-debt values, general level of FF, as well as such its constituents as the mobility of physiological processes, economy, anaerobic power, are integral key and informative parameters and constituents of the general structure of wrestlers' fitness. The studies revealed that they are interconnected with skill level and weight category of athletes, and change differently in the process of improving sports mastery and increasing body mass of combat athletes.
Improvement of wrestler FF structure with an increase of their skill level and in the annual training cycle is characterized by a decrease in the number of key functional parameters determining the result in special work capacity test.

The results of the work performed entitle us to believe that the system approach, methods of complex testing of athletes and modern methods of statistical analysis enable more efficient solution of the issues of control and management of wrestler functional fitness and special work capacity at the stage of maximum realization of individual capacities.

\section{Conclusions}

General level of FF, its integral components (anaerobic power, economy, mobility of physiological processes), along with the level of special work capacity, $\mathrm{O}_{2}$-debt values, are the key informative parameters and constituents of wrestler fitness general structure changing with alteration of skill level and weight categories of athletes.

An increase in the specific role of the key parameters determining skill level and special work capacity of wrestlers, economization of physiological processes are the most significant criteria for improving the structure of their FF.

\section{Conflict of interests.}

The authors declare no conflict of interest. 


\section{References}

1. Boyko VF, Danko GV. Physical preparation of wrestlers. Kiev: Olympic Literature; 2004. (In Russian).

2. Kolenkov OV, Pryimakov OO, Prystynskyi VM, Osiptsov AV. Modeling structure of special physical fitness of highly skilled wrestlers at the stage of maximum realization of individual capacities, Donetsk: Knowledge; 2012. (In Russian).

3. Pryimakov OO. Comparative characteristics structure physically prepared fighters high qualification light, medium and heavy weight category. Pedagogics, Psychology, Medical-Biological Problems of Physical Training and Sports, 2014; 9: 47-53. https://doi.org/10.5281/zenodo.10128

4. Milazzo N, Farrow D, Fournier JF. Effect of Implicit Perceptual-Motor Training on Decision-Making Skills and Underpinning Gaze Behavior in Combat Athletes. Perceptual and Motor Skills. 2016;123(1):300-323. https://doi.org/10.1177/0031512516656816

5. Malinsky II. Individual peculiarities of wrestlers anaerobic lactate capacities as one of the factors of their functional fitness. Science in the Olympic sport, 2000; 1: 79-85. (In Russian).

6. Barreto TD, Conceicao MRD, Souza DS. Exercise intensity and endurance performance: is aerobic energy expenditure the best choice? Journal of Applied Physiology. 2018;125(2):680-681.

7. Malatesta D, Lanzi S, Fernandez-Menendez A, Borrani F. Use aerobic energy expenditure instead of oxygen uptake to quantify metabolic rate and cost of exercise: intensity matters. Journal of Applied Physiology. 2018;125(2):679-679.

8. Danko GV. The impact of individual training loads on the state of wrestlers' work capacity. Physical education of students of creative specialties, 2004; 5: 9-15.

9. Pryimakov OO, Kolenkov OV, Machaidze EP. Interconnections of morphofunctional and speed-strength indices of physical fitness structure of highly skilled wrestlers. Pedagogics, Psychology, Medical-Biological Problems of Physical Training and Sports, 2006; 2: 99-103.

10.Anthierens A, Olivier N, Thevenon A, Mucci P. Trunk Muscle Aerobic Metabolism Responses in Endurance Athletes, Combat Athletes and Untrained Men. International Journal of Sports Medicine. 2019;40(7):434-439. https://doi.org/10.1055/a-0856-7207

11.Reljic D, Feist J, Jost J, Kieser M, Friedmann-Bette B. Rapid bodymasslossaffectserythropoiesisandhemolysisbutdoesnot impair aerobic performance in combat athletes. Scandinavian Journal of Medicine \& Science in Sports. 2016;26(5):507-517. https://doi.org/10.1111/sms.12485

12.Papassotiriou I, Nifli AP. Assessing performance in pre-season wrestling athletes using biomarkers. Biochemia Medica. 2018;28(2). https://doi.org/10.11613/bm.2018.020706

13.Burdukiewicz A, Pietraszewska J, Stachon A, Andrzejewska J. Anthropometric profile of combat athletes via multivariate analysis. Journal of Sports Medicine and Physical Fitness. 2018;58(11):1657-1665. https://doi.org/10.23736/s0022-4707.17.07999-3

14.Nikooie R, Cheraghi M, Mohamadipour F. Physiological determinants of wrestling success in elite Iranian senior and junior Greco-Roman wrestlers. Journal of Sports Medicine and Physical Fitness. 2017;57(3):219-226. https://doi.org/10.23736/s0022-4707.16.06017-5

15.Erkan Demirkan. The monitoring of weight fluctuation and hydration status in cadet wrestlers (ages 14-17) during a training camp period leading up to competition. International Journal of Wrestling Science, 2011; 1(2): 12-18.

16.Ferreira Marinho B, Vidal Andreato L, Follmer B, Franchini E. Comparison of body composition and physical fitness in elite and non-elite Brazilian jiujitsu athletes. Science \& Sports, 2016;31:129-34. https://doi.org/10.1016/j.scispo.2015.12.001

17.Roklicer R, Trivic T, Milovanovic I, Ostojic SM, Drid P. Fitness and anthropometric profiles of Serbian elite GrecoRoman wrestlers. Science \& Sports. 2020;35(2):115-116. https://doi.org/10.1016/j.scispo.2019.10.008

18.Kraemer William. The Physiological Basis of Wrestling: Implications for Conditioning Programs. The Strength and Conditioning Journal, 2004; 26(2): 10-15. https://doi.org/10.1519/00126548-200404000-00001

19.Rahmani-Nia F, Mirzaei B, Nuri R. Physiological profile of elite Iranian junior Greco-Roman wrestlers. International Journal of Fitness, 2007; 3: 49-54.

20.Romanenko V, Podrigalo L, Iermakov S, Rovnaya O, Tolstoplet E, Tropin Y, et al. Functional state of martial arts athletes during implementation process of controlled activity comparative analysis. PhysicalActivity Review. 2018;6:87-93. https://doi.org/10.16926/par.2018.06.12

21.Gierczuk D, Bujak Z, Cieslinski I, Lyakh V, Sadowski J. Response time and effectiveness in elite greco-roman wrestlers under simulated fight conditions. Journal of Strength and Conditioning Research. 2018;32(12):3433-3440. https://doi.org/10.1519/jsc.0000000000002868

22.Taggart A, Mullen S. Effects of Martial Arts Training on Motor Functioning: A Scoping Review. Journal of Sport \& Exercise Psychology. 2019;41:S22-S22.

23.Soto DAS, Aedo-Munoz E, Brito CJ, Camey S, Miarkao B. Making Decisions and Motor Actions with Technical Biomechanical Classifications in Male Judo Weight Categories. Journal of Human Kinetics. 2020;72(1):241-252. https://doi.org/10.2478/hukin-2019-0110

24.Pulido-Pedrero S, de la Vega-Marcos R, Fuentes-Garcia JP. Achievement motivation in elite combat athletes: computerised objective assessment. Revista De Psicologia Del Deporte. 2020;29(1):75-82.

25.Sudakov KV. Theory of functional systems. Moscow: Science; 1996. (In Russian).

26.World Medical Association Declaration of Helsinki: Ethical Principles for Medical Research Involving Human Subjects. JAMA, 2013;310:2191. https://doi.org/10.1001/jama.2013.281053

27.Mishchenko VS. Functional potentials of athletes. Kiev: Health; 1990. (In Russian).

28.Mishchenko V. Physiological monitoring of athletic training: current approaches and directions of improvement. Nauka $v$ olimpiyskom sporte, 1997; 1(6): 92-103. (In Russian).

29.Bellenger CR, Thomson RL, Howe PRC, Karavirta L, Buckley JD. Monitoring athletic training status using the maximal rate of heart rate increase. Journal of Science and Medicine in Sport. 2016;19(7):590-595. https://doi.org/10.1016/j.jsams.2015.07.006

30.Del Vecchio FB, Gondim DF, Arruda ACP. Functional movement screening performance of brazilian jiujitsu athletes from brazil: differences considering practice time and combat style. Journal of Strength and Conditioning Research. 2016;30(8):2341-2347. https://doi.org/10.1519/jsc.0000000000001324

31.Branco BHM, Lopes-Silva JP, Santos JFD, Julio UF, Panissa VLG, Franchini E. Monitoring training during four weeks of three different modes of high-intensity interval training in 
judo athletes. Archives of Budo. 2017;13:51-62.

32.Hecksteden A, Pitsch W, Julian R, Pfeiffer M, Kellmann M, Ferrauti A, et al. A New Method to Individualize Monitoring of Muscle Recovery in Athletes. International Journal of Sports Physiology and Performance. 2017;12(9):1137-1142. https://doi.org/10.1123/ijspp.2016-0120

33.Sperlich B, Holmberg HC. The Responses of Elite Athletes to Exercise: An All-Day, 24-h Integrative View Is Required! Frontiers in Physiology. 2017;8. https://doi.org/10.3389/fphys.2017.00564

34.Borovikov VP, Ivchenko GI. Prognostication in the system of Statistica in the environment of Windows. Moscow: Finances and statistics; 2006. (In Russian).

35.Pryimakov O, Iermakov S, Kolenkov O, Samokish I, Juchno J. Monitoring of functional fitness of combat athletes during the precompetitive preparation stage. Journal of Physical Education and Sport, 2016, 16(2): 551 -561. https://doi.org/10.7752/jpes.2016.02087

36. Pryimakov OO, Kolenkov OV. Model characteristics of special work capacity level dependence on skill level and weight category of wrestlers. Physical Education of Students of Creative Specialties, 2006; 5: 51-60. (In Russian).

37.Pryimakov OO. Model characteristics of the structure physical training fighters qualifications. Pedagogics, Psychology, Medical-Biological Problems of Physical Training and Sports, 2013; 6: 36-42. https://doi.org/10.6084/m9.figshare.714938
38.Akhlaghi H, Heydarinezhad S, Poor AM, Marashian SH. The Effect of Moral Orientation on the Performance of Iranian Wrestlers: Explaining the Model and Providing a Strategy. Annals of Applied Sport Science. 2020;8(1). https://doi.org/10.29252/aassjournal.719

39. Caloglu M, Yuksel O. The Effect of Cross Fit Training on Anaerobic Power and Dynamic Balance of Greco-Roman and Freestyle Wrestlers. International Journal of Applied Exercise Physiology. 2020;9(1):122-132.

40.Klimczak J, Kalina RM, Jagiello W. Fun forms of martial arts in diagnosing and reducing aggressiveness - mental effects of a one-day course for Polish animators of sport. Health and martial arts in interdisciplinary approach, 2015. P. 187-189.

41.Jagiełło W, Kruszewski A. Morphological Diversification of Competitors Training Greco-Roman Style of Wrestling. Archives of Budo, 2009; 5: 147-153.

42.Kalina RM, Jagiello W. Non-apparatus, Quasi-apparatus and Simulations Tests in Diagnosis Positive Health and Survival Abilities. In: Ahram T, editor. Advances in Human Factors in Sports, Injury Prevention and Outdoor Recreation, Ahfe 2017. Advances in Intelligent Systems and Computing, 2018; 603. p. 121-128.

43.Jagiełło W. Perkal's method of natural indicators in the assessment of internal proportions of body composition in persons practicing combat sports - a review. Arch Budo, 2019; 15: 187-193.

\section{Information about the authors:}

Oleksandr Pryimakov; (Corresponding author); Doctor of Biological Sciences, Professor; http://orcid.org/0000-0003-0351486X; alprim7491@gmail.com; Institute of Physical Culture Sciences, Szczecin University; al. Piast 40B, Block 6, 71-065 Szczecin, Poland.

Sergii lermakov; Doctor of Pedagogical Sciences, Professor; http://orcid.org/0000-0002-5039-4517; sportart@gmail.com; Department of Sport, Branch of Team Sports Games, Volleyball Laboratory, Gdansk University of Physical Education and Sport; Kazimierza Górskiego 1, 80-336 Gdańsk, Poland.

Jerzy Eider; Doctor of Pedagogical Sciences, Professor, http://orcid.org/0000-0002-8401-6442; jerzy.eider@usz.edu.pl; Institute of Physical Culture Sciences, Szczecin University; al. Piast 40B, Block 6, 71-065 Szczecin, Poland.

Stanislav Prysiazhniuk; Doctor of Pedagogical Sciences, Professor; http://orcid.org/0000-0002-3017-0268; stas046@ukr.net; Department of Life Safety and Physical Education, University of Telecommunications; Volodimirska str., 40/2/4, 01030, Kiev, Ukraine.

Natalija Mazurok; Master Degree “Physical Education and Sport”, https://orcid.org/0000-0001-7346-1156; natprim75@gmail. com; National Pedagogical Dragomanov University; Pyrogova str., 9. Kyiv, 01601,Ukraine.

\section{Cite this article as:}

Pryimakov O, lermakov S, Eider J, Prysiazhniuk S, Mazurok N. Physiological criteria of functional fitness and determinants of physical work capacity of highly skilled wrestlers. Physical Education of Students, 2020;24(4):205-212. https://doi.org/10.15561/20755279.2020.0403

This is an Open Access article distributed under the terms of the Creative Commons Attribution License, which permits unrestricted use, distribution, and reproduction in any medium, provided the original work is properly cited http://creativecommons.org/licenses/by/4.0/deed.en

Received: 18.06.2020

Accepted: 23.07.2020; Published: 30.08.2020 